\title{
A Study of Carbon-Tungsten Composite Electrodes as Cathode Materials for Molten Salt Batteries
}

\author{
Wishvender K. BEHL, David D. BEALS and Galen R. Frysinger \\ Power Sources Division, Electronic Components Laboratory Usaecom, \\ Fort Monmouth, New Jersey.
}

Received Sept. 11, 1969

\begin{abstract}
This paper describes a study of porous carbon and carbontungsten composite electrodes as cathode materials for molten salt batteries. The cathode capacities of these electrodes were determined from a study of the charge and discharge curves of the cells:

$\mathrm{Li}-\mathrm{Al} / \mathrm{LiCl}-\mathrm{KCl} / \mathrm{C}$

$\mathrm{Li}-\mathrm{Al} / \mathrm{LiCl}-\mathrm{KCl} / \mathrm{C}-\mathrm{W}$

The tungsten content in the composite electrode was varied from 10 to 75 weight percent. The cathode capacity of the $\mathrm{C}-\mathrm{W}$ composite electrode obtained in $\mathrm{LiCl}-\mathrm{KCl}$ was compared with the capacity obtained in the following halide electrolytes: $\mathrm{LiCl}-\mathrm{RbCl}, \mathrm{LiCl}-\mathrm{CsCl}, \mathrm{LiCl}-\mathrm{KCl}-\mathrm{RbCl}$, $\mathrm{LiCl}-\mathrm{KCl}-\mathrm{BaCl}_{2}, \mathrm{LiBr}-\mathrm{KBr}, \mathrm{LiBr}-\mathrm{RbBr}, \mathrm{LiBr}-\mathrm{BaBr}_{2}, \mathrm{LiBr}-\mathrm{LiCl}$. The discharge curves in these electrolytes are also presented.
\end{abstract}

\section{Introduction}

During the past few years there has been considerable interest in the development of a high energy density battery with a capacity in the range of 150-200 watt-hours per pound. This interest has been mainly stirred because of the need of such a battery for a possible use in future electric vehicles. Since no aqueous electrolyte system is, as yet, capable of giving an energy density within this range, attention has been focused on nonaqueous systems consisting of organic and molten salt electrolytes. The former has been extensively investigated ${ }^{1), 2}$ ) but has the disadvantage of very low rates as well as poor shelf life. The molten salts appear more attractive because of their high conductance as well as their thermal stability. The conductivities $^{3}$ ) of molten salts are 10-100 times higher than those obtained in a queous systems which makes it possible to obtain high discharge rates and low IR losses. Several molten salt systems capable of giving the desired energy densities for vehicle propulsion have been proposed, e.g., sodium-sulphur cell ${ }^{4}$ ), lithium-chlorine cell $^{5), 6)}$ Sohio molten salt cell ${ }^{7)}$ and lithium-tellurium cell $^{8)}$. The use of porous carbon ${ }^{9)}$ and carbontungsten composite ${ }^{10}$ ) electrodes as cathode materials has been suggested for molten slat batteries, but no systematic study of these electrode materials has been reported in literature. In the present studies, charge-discharge characteristics of porous carbon and carbontungsten composites were studied employing cells of the type

$$
\begin{array}{rr}
\mathrm{Li}-\mathrm{Al} / \mathrm{LiCl}-\mathrm{KCl} / \mathrm{C} & \text { I } \\
\mathrm{Li}-\mathrm{Al} / \mathrm{LiCl}-\mathrm{KCl} / \mathrm{C}-\mathrm{W} & \text { II }
\end{array}
$$

Porous carbon electrodes of different density and surface areas were used and the composition of tungsten in the composite electrodes was varied from 10 to 75 weight percent. The study was 
also extended to the following halide electrolytes: $\mathrm{LiCl}-\mathrm{RbCl}$, $\mathrm{LiCl}-\mathrm{CsCl}, \mathrm{LiCl}-\mathrm{BaCl}_{2}$, LiCl$\mathrm{KCl}-\mathrm{RbCl}, \mathrm{LiCl}-\mathrm{KCl}-\mathrm{BaCl}_{2}, \mathrm{LiBr}-\mathrm{KBr}, \mathrm{LiBr}-\mathrm{RbBr}$, $\mathrm{LiBr}-\mathrm{BaBr}_{2}$ and $\mathrm{LiBr}-\mathrm{LiCl}$.

\section{Experimental}

\subsection{The Cell}

The cell and the electrode assembly are shown in Fig. 1. The cell consisted of an 8 inch long pyrex tubing (1-inch diameter) closed at one end and having a side arm $(8 \mathrm{~mm}$ dia pyrex tubing) near the top. The top of the cell was closed with a No. 6 stopper with five holes to support the different electrodes, thermocouple and a gas bubbling tube.

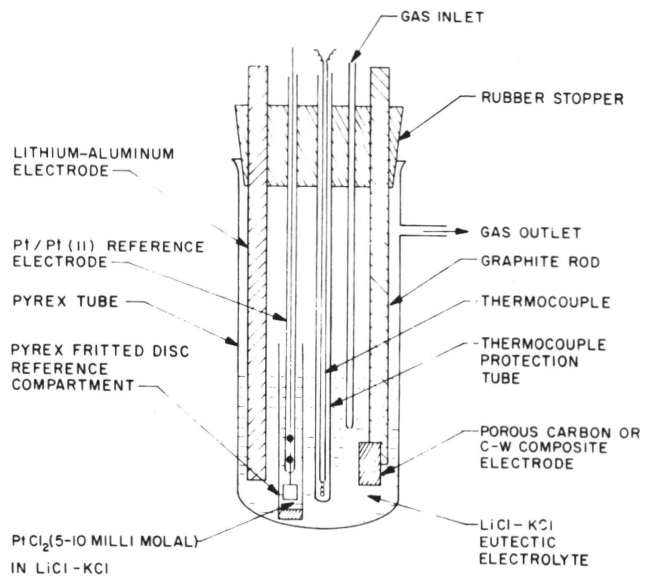

Fig. 1 Cell assembly

\subsection{Electrolyte Preparation and Purification}

Reagent grade chemicals were used. A 60-80 g sample of the lithium chloridepotassium chloride eutectic mixture (59:41 moler percent) was transferred to the cell and heated to $100^{\circ} \mathrm{C}$ in a flowing atmosphere of hydrogen chloride gas for about $8-10$ hours. The temperature was then slowly increased to the melting point of the eutectic $\left(352^{\circ} \mathrm{C}\right)$ and then raised to $450^{\circ} \mathrm{C}$. The bubbling of hydrogen chloride as followed by chlorine gas was continued for another 1-2 hours and then replaced by argon gas which removed the excess of hydrogen chloride gas dissolved in the melt. At this stage the electrode assembly was lowered into the melt and a flowing atmosphere of argon was maintained throughout the duration of the experiment. A similar procedure was adopted for the preparation of other halide electrolytes. In the case of $\mathrm{LiBr}-\mathrm{LiCl}$ and bromide melts, hydrogen chloride gas was replaced by hydrogen bromide gas.

\subsection{Electrodes}

Porous carbon and carbon-tungsten composite electrodes used in the present study were supplied by Ling-Temco-Vought Inc., Dallas, Texas. The porous carbon electrodes are made by the pyrolysis of a polymer whose major constituent is polyvinylidene chloride. The porous carbons so obtained have high internal surface areas of the order of $300-500 \mathrm{~m}^{2} / \mathrm{g}$. The surface areas of the carbon-tungsten composite with a tungsten content of 50-75 wt. $\%$ are relatively small (about $10 \mathrm{~m}^{2} / \mathrm{g}$ ). The surface areas were measured by using the ORR surfacearea and pore-volume analyser, Model 2100, Micromeritics Instrument Corporation.

In the present studies, a $7 / 8^{\prime \prime} \times 3 / 8^{\prime \prime} \times 1 / 8^{\prime \prime}$ piece of porous carbon or carbon-tungsten composite was sealed to a $1 / 4^{\prime \prime}$ dia. graphite rod using Union Carbide $\mathrm{C}-9$ carbon cement. The seal was then matured by baking the electrode in an inert atmosphere of argon gas.

The lithium-aluminum electrode consisted of a $1 / 4^{\prime \prime}$ dia. aluminum rod on which lithium was electrolytically deposited from the $\mathrm{LiCl}-\mathrm{KCl}$ eutectic by passage of a constant current of 200 $\mathrm{mA}$ for a period of 1-2 hours.

At $\mathrm{Pt} / \mathrm{Pt}(11)$ couple was used as a reference electrode in chloride melts while a $\mathrm{Ag} / \mathrm{Ag}(1)$ couple was used as a reference in bromide melts. Pt(11) and $\operatorname{Ag}(1)$ concentrations (5-10 millimolal) in the reference compartment were coulometrically generated by anodic dissolution of platinum and silver metals respectively at small current densities $\left(5 \mathrm{ma} / \mathrm{cm}^{2}\right)$. The reference electrode was isolated from the other electrodes by use of a pyrex fritted disc compartment.

The tungsten wire electrode used in the cyclic voltammetric experiments was prepared by sealing a $1 \mathrm{~mm}$ tungsten wire in uranium glass so that only a $5 \mathrm{~mm}$ length of the wire was exposed. 
A 1/4" dia. graphite rod was used as the auxiliary electrode.

\subsection{Apparatus}

A wire wound cylindrical furnace was used to heat the cell assembly and temperature of the cell was maintained at $450 \pm 2{ }^{\circ} \mathrm{C}$ (unless otherwise indicated) using an API Temp Tendor Model 734 temperature controller. The temperature was measured with a chromel-alumel thermocouple.

An Anotrol Model 4100 potential controller was used in the galvanostatic mode to supply constant currents from 1-1000 milliamperes. The charge and discharge curves were recorded on a Moseley Model 7100B strip chart recorder.

The voltammetric scans were performed with a Tacussel Model PIT-20-2A potentiostat coupled with a GSTP-2 function generator and recorded on a Tektronix Type 564 storage oscilloscope.

\section{Results and Discussion}

Typical discharge curves for cells I and II are shown in Fig. 2. Both cells were charged at a constant current of $200 \mathrm{~mA}$ to a voltage of 3.2 volts. The potential of the lithium-aluminum negative electrode was measured versus a $\mathrm{Pt} / \mathrm{Pt}^{11)}$ reference electrode and was found to remain constant at $2.9 \pm 0.01$ volts during the charge and discharge of cells I and II (Fig. 3).

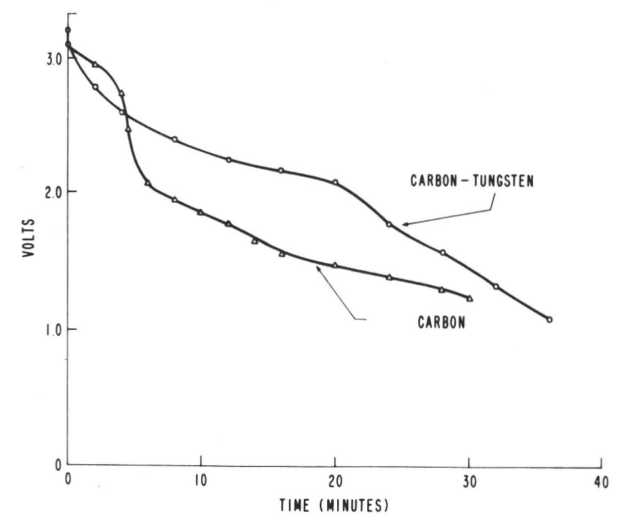

Fig. 2 Typical discharge curves in $\mathrm{LiCl}-\mathrm{KCl}$ using carbon and C-W composites (50:50) as cathodes, discharge current: $200 \mathrm{~mA}$

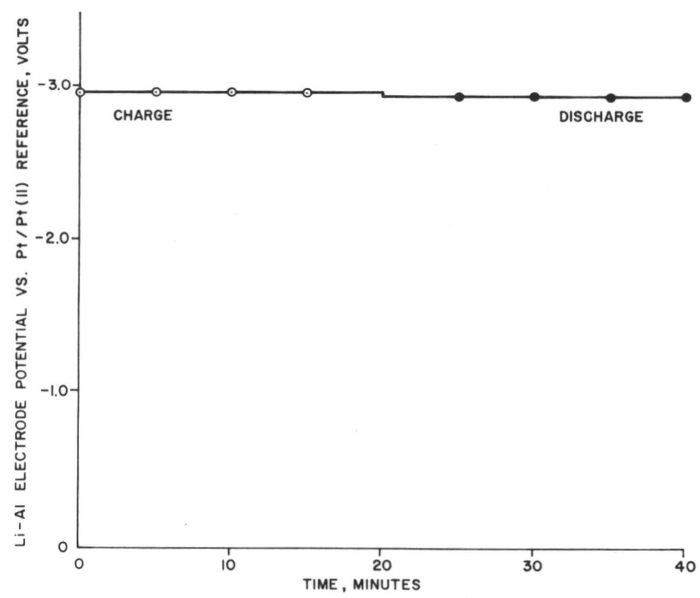

Fig. 3 Potential of the Li-Al electrode versus a $\mathrm{Pt} / \mathrm{Pt}(11)$ reference during charge and discharge

Since lithium is known ${ }^{11}$ ) to form an alloy with aluminum, the deposition of lithium on an aluminum rod leads to the formation of the alloy (LiAl) on the surface and as more and more of lithium is deposited during the charging of cells I and II, lithium diffuses into the body of aluminum so that the composition of lithium. aluminum alloy remains unchanged on the surface. This process is reversed during the process of discharge. This mechanism of diffusion of lithium into the body of aluminum explains the constancy of the potential of the lithium-aluminum negative electrode during charge and discharge. Further the lithiumaluminum alloy is solid at the working temperature $\left(450^{\circ} \mathrm{C}\right)$ of cells I and II. The use of this alloy as the negative electrode, therefore, not only eliminates the difficulties involved in the handling of corrosive liquid lithium metal, but also considerably decreases the solubility of lithium in lithium chloride-potassium chloride eutectic and other lithium containing electrolytes.

Since the lithium-aluminum electrode exhibits flat voltage characteristics, the discharge curves shown in Fig. 2 can therefore be entirely attributed to the discharge characteristics of the porous carbon and carbon-tungsten composite electrodes. The carbon electrode shows a sharp fall in the beginning of the discharge curve and then gradually decreases to the cut-off voltage of 
1.0 volt. The carbon-tungsten composite electrode (50:50 wt. \%) on the other hand shows a relatively flat discharge plateau in the beginning of the discharge curve and then falls down to the cut-off voltage. Similar discharge curves were obtained with composite electrodes with a higher tungsten content. However, if the tungsten content was less than 40 percent by weight, the discharge curves resembled those obtained with porous carbon electrodes.

To compare the performance of the different cathodes used in the present study, the cathode capacities were determined in each case by use of the equation:

$$
\mathrm{C}=\frac{\mathrm{E} \times \mathrm{t} \times \mathrm{I}}{\mathrm{V}}
$$

Where $\mathrm{C}$ is the cathode capacity in watt-hr/in ${ }^{3}, \mathrm{E}$ is the voltage of the cell in volts, $t$ is the time in hours, I is the discharge current in amperes, and $\mathrm{V}$ is the volume in cubic inches. The product (E) $x(t)$ was simply obtained by integration of the voltage-time discharge curve and discharge current, I, was directly measured using an ammeter in the circuit. The volume of the electrode, $\mathrm{V}$, was obtained from its dimensions $\left(7 / 8^{\prime \prime} \times 3 / 8^{\prime \prime} \times\right.$ $\left.1 / 8^{\prime \prime}\right)$ and was equal to $0.041 \mathrm{in}^{3}$ in each case.

The cathodes capacities obtained by use of equation 1 with carbon and carbon-tungsten composite electrodes are summarized in Table 1. The densities of the cathodes are also included in this Table. These were obtained by dividing the weight of porous carbon or carbon-tungsten composite by its volume in cubic centimeters.

Table 1 Capacity of C-W Cathodes in LiCl-KCl

\begin{tabular}{l|l|c}
\hline \hline $\begin{array}{l}\text { Tungsten } \\
\text { content } \\
\text { (wt. \%) }\end{array}$ & $\begin{array}{l}\text { Cathode } \\
\text { density } \\
\text { (g/cc) }\end{array}$ & $\begin{array}{l}\text { Cathode } \\
\text { capacity } \\
\text { (Watt-hr/in } 3)\end{array}$ \\
\hline None & 0.75 & 3.77 \\
None & 1.24 & 1.67 \\
10 & 0.91 & 2.17 \\
25 & 1.04 & 1.75 \\
40 & 1.32 & 1.65 \\
50 & 1.43 & 5.65 \\
66 & 2.02 & 5.03 \\
75 & 2.22 & 5.37 \\
\hline
\end{tabular}

In case of porous carbon electrodes, the internal surface areas are quite high (300-500 $\mathrm{m}^{2} / \mathrm{g}$ ) so that a large amount of energy can be stored on the surface. The storage of the charge is thus mainly capacitative, however, it is likely that the chloride ions are partly discharged, but due to the strong adsorption on carbon do not appear as a gas. It was observed that porous carbon electrodes with low density (high surface area) yielded higher cathode capacities in Cell I.

In case of the composite electrodes, the storage of the energy is capacitative as well as electrochemical. The incorporation of the tungsten metal in the porous carbon considerably decreases the internal surface area which is of the order of $10 \mathrm{~m}^{2} / \mathrm{g}$ only and thus the capacitative part of the energy storage is relatively small. On charge, the tungsten metal in the composite electrode is oxidized to tungsten chloride and on discharge this reaction is reversed. This electrochemical reaction presumably occurs on the surface and is also accompanied by a small amount of capacitative storage on carbon in the composite electrode. The cathode capacities of the composite electrodes with a tungsten content of 10-75 weight percent were determined in $\mathrm{LiCl}-\mathrm{KCl}$ eutectic at $450^{\circ} \mathrm{C}$ and are summarized in Table 1 . It was found that the capacities of the composite electrodes with a tungsten content of 50 weight percent or more were higher than those obtained with porous carbon electrodes.

The carbon-tungsten composite electrodes were also studied in other halide electrolytes by use of the cell:

\section{$\mathrm{Li}-\mathrm{Al} / \mathrm{LiX}-\mathrm{MX} / \mathrm{C}-\mathrm{W} \quad$ III}

Where $\mathrm{M}$ is $\mathrm{K}^{+}, \mathrm{Rb}^{+}, \mathrm{Cs}^{+}$or $\mathrm{Ba}^{++}$and $\mathrm{X}$ is $\mathrm{C \Gamma}$ or $\mathrm{Br}^{-}$. For purposes of comparison, the composite electrodes with tungsten content of 66 wt. \% were used. The density of these electrodes prepared in separate batches varied within 5 percent. This slight variation in density is probably due to the non-uniform distribution of tungsten in the composite electrodes. The internal surface area of these electrodes was found to be of the order of $10^{2} / \mathrm{g}$.

The discharge curves of the carbon-tungsten composite electrodes at a discharge current of 
Table 2 Capacity of C-W (34:66 wt. \%) cathodes in halide electrolytes

\begin{tabular}{l|l|c|c|c}
\hline \hline \multicolumn{1}{c|}{ Electrolyte } & \multicolumn{1}{|c|}{$\begin{array}{c}\text { Composition } \\
(\text { mole } \%)\end{array}$} & $\begin{array}{c}\text { Melting point } \\
\left({ }^{\circ} \mathrm{C}\right)\end{array}$ & $\begin{array}{c}\text { Cathode density } \\
(\mathrm{gm} / \mathrm{cc})\end{array}$ & $\begin{array}{c}\text { Cathode capacity } \\
\left(\mathrm{Watt}-\mathrm{hr} / \mathrm{in}^{3}\right)\end{array}$ \\
\hline LiCl-KCl $(3,12,13)$ & $59: 41$ & 352 & 2.02 & 5.03 \\
LiCl-RbCl $(3,13)$ & $59.3: 41.7$ & 318 & 2.01 & 4.50 \\
LiCl-CsCl (3, 13) & $59.3: 40.7$ & 323 & 2.02 & 2.68 \\
LiCl-KCl-RbCl (14) & $65.4: 17.3: 17.3$ & 305 & 2.02 & 2.34 \\
LiCl-KCl-BaCl $(15)$ & $54.26: 30.36: 6.38$ & 320 & 1.97 & 0.25 \\
LiBr-KBr (16) & $68: 32$ & 320 & 2.01 & 4.64 \\
LiBr-RbBr (17) & $59: 41$ & 259 & 2.06 & 1.0 \\
LiBr-BaBr $(18)$ & $75: 25$ & 483 & 2.08 & 0.4 \\
LiBr-LiCl (19) & $75: 25$ & 522 & 2.07 & 1.28 \\
\hline
\end{tabular}

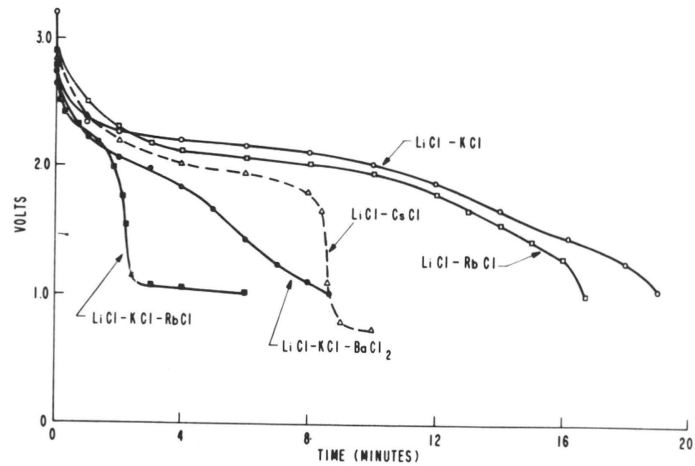

Fig. 4 Discharge curves in chloride melts using C-W composites $(34: 66)$ as cathodes, discharge current: $500 \mathrm{~mA}$

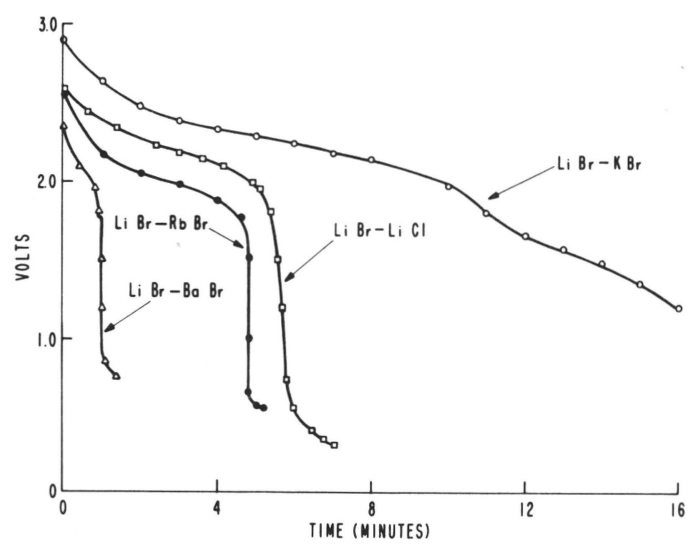

Fig. 5 Discharge curves in bromide melts using C-W composite (34:66) as cathodes, discharge current: $500 \mathrm{~mA}$
$500 \mathrm{~mA}$ is various halide electrolytes are shown in Figs. 4 and 5. The discharge curves in $\mathrm{LiBr}$ $\mathrm{BaBr}_{2}$ and $\mathrm{LiCl}-\mathrm{LiBr}$ were recorded at $550^{\circ} \mathrm{C}$ and $575^{\circ} \mathrm{C}$ respectively because of their high melting point. All other discharge curves were recorded at $450^{\circ} \mathrm{C}$. Similar discharge curves were obtained in each case, but the cathode capacities obtained by use of equation 1 depended to a large extent on the electrolyte used. The data for the different electrolytes are summarized in Table 2. The cathode capacities in $\mathrm{LiCl}-\mathrm{KCl}, \mathrm{LiCl}-\mathrm{RbCl}$ and $\mathrm{LiBr}-\mathrm{KBr}$ were comparable and higher than those obtained in other electrolytes.

\section{Electrode Reactions}

A preliminary study of the electrode reactions at a tungsten wire electrode was made bý cyclic voltammetry. A three electrode system was used. These electrodes have been described in the experimental section. The electrolyte was divided into three separate compartments by use of pyrex tubes with fritted-glass bottoms. The cyclic voltammogram obtained in $\mathrm{LiCl}-\mathrm{KCl}$ is shown in Fig. 6. The sweep was started in the anodic direction from the rest potential of -0.4 volts versus $\left.\mathrm{Pt} / \mathrm{Pt}^{11}\right)$ reference. Two anodic peaks were observed beginning at -0.1 and +0.3 volts versus $\mathrm{Pt} / \mathrm{Pt}^{11}$ ) reference. The second peak is close to the chlorine/chloride reversible potential obtained by Laitinen and $\mathrm{Liu}^{20}$ ) in $\mathrm{LiCl}-\mathrm{KCl}$ and can therefore be ascribed to the oxidation of chloride ions to chlorine. The first peak is therefore due to the dissolution of 


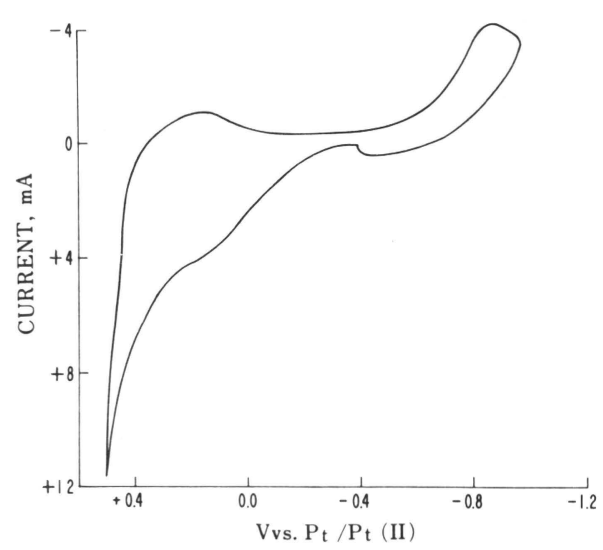

Fig. 6 Cyclic voltammogram in $\mathrm{LiCl}-\mathrm{KCl}$, scan rate: 6 volts/sec

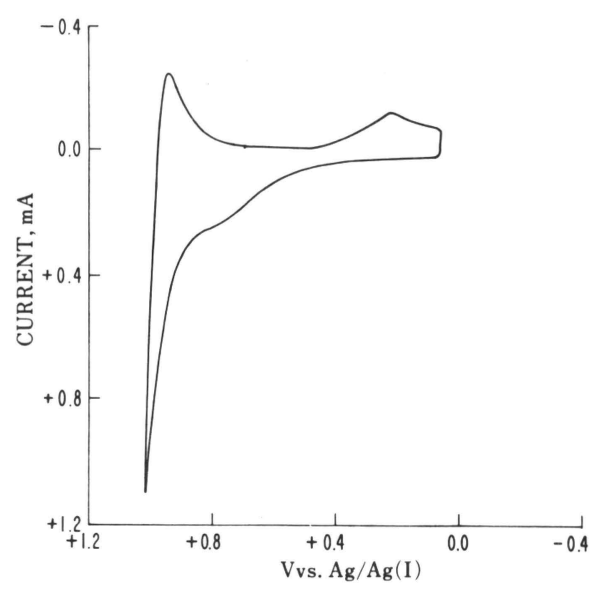

Fig. 7 Cyclic voltammogram in LiBr-KBr scan rate: 1 volt $/ \mathrm{sec}$

tungsten metal. On reversing the direction of sweep, two peaks corresponding to the reduction of chlorine and the reduction of tungsten species in solution were observed. A similar voltammogram was obtained in $\mathrm{LiBr}-\mathrm{KBr}$ eutectic and is shown in Fig. 7. In this case the potentials of the tungsten working electrode are referred to $\mathrm{Ag} / \mathrm{Ag}^{1)}$ reference. Since the anodic and cathodic peaks of tungsten in $\mathrm{LiCl}-\mathrm{KCl}$ and also in $\mathrm{LiBr}-\mathrm{KBr}$ are separated by about $0.6-0.8$ volts, a certain degree of irreversibility of the electrode reaction is indicated. Further work is under progress to characterize the tungsten species formed in solution and to specify the electrode reactions on charge and discharge at carbon-tungsten composite electrodes.

\section{Summary}

The carbon-tungsten composite electrodes were found to be useful cathode materials for molten salt batteries. The discharge curves obtained with the composite electrodes (tungsten content $50 \mathrm{wt}$. percent or more) exhibited a relatively flat plateau while no such plateau was observed with high surface area carbon electrodes. The capacities of the composite electrodes in $\mathrm{LiCl}-\mathrm{KCl}, \mathrm{LiCl}-\mathrm{RbCl}$ and $\mathrm{LiBr}-\mathrm{KBr}$ were comparable and higher than those obtained in other halide electrolytes.

Acknowledgements: The authors are grateful to Mr. Madison Reed of Ling-Temco-Vought, Inc., for supplying the composite electrodes and to Dr. Carl E. Johnson of Argonne National Laboratory for making available the results of his phase diagram studies of some ternary halide systems prior to publication. The authors would also like to thank Mr. J. J. Murphy for helpful discussions, and Mr. A. J. Hack for carrying out surface area measurements of the porous carbon and carbon tungsten composite electrodes.

\section{References:}

1) R. Jasinski, "High Energy Batteries" (1967), Plenum Press, New York.

2) K. H. M. Braeuer, J. A. Harvey, "Organic Electrolyte High Energy Density Batteries, A Status Report," May (1967), (DA 654 813).

3) G. J. Janz, "Molten Salt Handbook" (1967), Academic Press, New York.

4) N. Weber, J. T. Kummer, Proc. Ann. Power Sources Conf. 21, 37 (1967).

5) D. A. J. Swinkles, J. Electrochem. Soc. 113, 6 (1966).

6) H. A. Wilcox, Proc. Ann. Power Sources Conf. 21, 39 (1967).

7) R. A. Rightmire, A. L. Jones, Proc. Ann. Power Sources Conf. 21, 42 (1967).

8) H. Shimotake, G. L. Rogers, E. J. Cairns, "Performance Characteristics of Lithium-Tellurium Cell" (1967), presented at the Electrochemical Society Meeting, Chicago, Illinois.

9) J. W. Sprague, D. L. Boos, D. L. Beals, R. L. Rowland, R. A. Rightmire, "Active Carbon Plate Cathodes for Molten Salt Batteries," (1966), presented at the Electrochem. Soc. Meeting, Philadelphia, Pa.

10) E. S. Buzzelli, "A Sohio Secondary Molten Salt Battery, " (1967), The Proceedings of the 1967 Advances in Battery Technology Symposium, 
California-Nevada Section of the Electrochemical Society, December.

11) Hansen, M., "Constitution of Binary Alloys" (1958), McGraw Hill Inc., New York.

12) H. A. Laitinen, W. S. Ferguson, R. A. Osteryoung, J. Electrochem. Soc. 104, 516 (1957).

13) T. W. Richards, W. B. Meldrum, J. Am. Chem. Soc. 39, 1816 (1917).

14) C. E. Johnson, Private Communication.

15) M. A. Zakharchenko, K. V. Gontar, Zh. Neogran.
Khim 7, 1964 (1962).

16) P. D. Garn, Bell Lab Record 33, 452 (1955).

17) S. D. Gromakov, L. M. Gromakova, Zh. Fiz. Khim 27, 1545 (1953).

18) E. Kordes, Z. Anorg. Allgem. Chem. 167, 97 (1927).

19) A. A. Botschwar, Z. Anorg. Allgem. Chem. 210, 163 (1933).

20) H. A. Laitinen, C. H. Liu, J. Am. Chem. Soc. 80, 1015 (1958).

\title{
Roles of Alkaline Metal Ions at Anodic Oxidation of Aluminium
}

\author{
Michiko Shimura, Sakae Taj ima \\ Faculty of Engineering, Tokyo Metropolitan University, \\ 2-1-1 Fukazawa, Setagaya-ku, Toky o
}

Received Jan. 12, 1970.

\begin{abstract}
Roles of alkaline metal ions at anodic oxidation of aluminium were investigated in aqueous bisulfates $-\mathrm{NH}_{4}{ }^{+}, \mathrm{Na}^{+}-, \mathrm{K}^{+}$- and Cs-bisulfates. Crystals have been deposited on the film by anodic oxidation when a small amount of bisulfate electrolyte was used. The crystals were identified as $\mathrm{NH}_{4}-$, Na-, $\mathrm{K}$ - or Cs-alum by X-ray diffraction method.

Transient behavior was investigated at constant current or constant voltage in 1.8 molal $\mathrm{CsHSO}_{4}$ and in $\mathrm{H}_{2} \mathrm{SO}_{4}$ of the same $\mathrm{pH}$ value used as a reference electrolyte. As the result, (1) in case of constant current density, V-t curves were identical at the increasing region both for $\mathrm{CsHSO}_{4}$ and $\mathrm{H}_{2} \mathrm{SO}_{4}$. Therefore, the decrease of the specific resistance of the barrier layer was deduced to depend only on the $\mathrm{pH}$ of the electrolyte. (2) Alkaline metal ion had no influence upon the pore initiation process of the anodic oxide film. Contrary to $\mathrm{H}^{+}$ion, alkaline metal ion is never adsorbed on the anodic oxide film against the field.
\end{abstract}

